\title{
Taking Care of Her: A Pilot Feasibility Study of a Caregiver Intervention for Women with Advanced Stage Ovarian Cancer
}

\author{
Frances Marcus Lewis ${ }^{1,2}$, Zainab Alzawad2, Kristin Griffith ${ }^{2}$, Hebah Almulla², Pei-Chin Wu2, \\ Nai-Ching Chi' ${ }^{2}$, Ellen H. Zahlis ${ }^{2}$, Mary Ellen Shands ${ }^{2}$ \\ ${ }^{1}$ Public Health Sciences Division \& Clinical Research Division, Fred Hutchinson Cancer Research Center, Seattle, USA \\ ${ }^{2}$ Department of Family and Child Nursing, University of Washington, Seattle, USA \\ Email: *fmlewis@uw.edu
}

How to cite this paper: Lewis, F.M., Alzawad, Z., Griffith, K., Almulla, H., Wu, P.-C., Chi, N.-C., Zahlis, E.H. and Shands, M.E. (2017) Taking Care of Her: A Pilot Feasibility Study of a Caregiver Intervention for Women with Advanced Stage Ovarian Cancer. Journal of Cancer Therapy, $\mathbf{8}$, 472-489.

https://doi.org/10.4236/jct.2017.85041

Received: April 5, 2017

Accepted: May 23, 2017

Published: May 26, 2017

Copyright $\odot 2017$ by authors and Scientific Research Publishing Inc. This work is licensed under the Creative Commons Attribution International License (CC BY 4.0).

http://creativecommons.org/licenses/by/4.0/ c) (i) Open Access

\begin{abstract}
The purpose of this study is to examine the feasibility and short-term impact of a fully manualized, telephone-delivered intervention for spouse caregivers, Taking Care of Her (TCH). A total of 12 study participants from the Pacific NW were enrolled whose wife was diagnosed with Stage III ovarian cancer within 8 months. Feasibility was confirmed by rates of recruitment and retention; the quality of delivery of the intervention by telephone; and through data obtained on program acceptability during follow up exit interviews. Outcomes from the within-group analysis revealed improvements on standardized measures of spouses' and patients' depressed mood and anxiety; marital communication about the cancer; caregivers' skills and confidence to manage the emotional toll of the illness on themselves and wives; and wives' positive appraisal of spousal support. Study results suggest that the TCH Program has the potential to positively affect both spouse caregiver and patients' adjustment to recently diagnosed advanced ovarian cancer. Telephone delivery holds promise for sustainability. A future clinical trial with a larger study sample is warranted.
\end{abstract}

\section{Keywords}

Advanced Ovarian Cancer, Couple Adjustment, Spouse Caregiver Intervention

\section{Introduction}

Ovarian cancer is an aggressive cancer that accounts for more deaths in women than any other cancer of the female reproductive system [1]. The age-specific incidence shows a steady increase to age 70, starting at 2 in every 100,000 women 
aged 20 - 29 years and rising to 55 in 100,000 at 70 years of age; about half who are diagnosed are 63 years or older [1] [2].

Despite advances in medical treatment, the emotional impact of the disease is substantial for both the patient and her spouse caregiver. [Spouse is an inclusive term that includes both female and male intimate partners.] Spouse caregivers' greatest concerns, regardless of age group, is their wives' well-being [3]. Spouse caregivers also report feeling like "deer in the headlights" and do not know what to say or do to support the patient nor how to manage the distress of the disease on themselves, the patient, or their relationship [4] [5] [6]. Rates of depressed mood and anxiety are significantly elevated in both patient and caregiver and both equate the diagnosis with an inevitable death sentence [7] [8] [9] [10]. The illness also deleteriously affects the couple as a dyad: it causes them to disconnect from each other, emotionally struggle on their own, constrains their communication about the illness with each other, and leaves the patient feeling abandoned, misunderstood, or unsupported [11] [12].

To date, there has been only one clinical trial that has attempted to assist the spouse caregiver in managing this illness but that trial emphasized symptom assessment, symptom management, and general relaxation skills. However, that same trial did not focus on the caregiver's competencies to interpersonally support the patient [13]. Further, despite the impact of the illness on the spouse caregiver's well being, no study has helped equip the caregiver with a broad range of self-care skills during early diagnosis and treatment. Instead the emphasis in most caregiver research has been and continues to be on helping the caregiver interpret and manage the patient's medications and symptoms [14] [15]. Even when intervention studies have included couples impacted by other gynecologic cancers (breast, cervical), very few have significantly improved the quality of interpersonal support or communication between the patient and spouse caregiver about the cancer and none have measured the impact of the intervention on spouse caregivers' skills or confidence to manage the toll of the cancer on themselves, the patient or their relationship [16] [17].

The intervention, the Taking Care of Her (TCH) Program was designed by the current team to be responsive to limitations in prior studies. The $T C H$ is a fully scripted, 5-session, telephone-delivered skill- and efficacy-building educational counseling program that is delivered directly to a spouse caregiver with an expected diffusion of benefit to the patient.

\section{Research Strategy}

Despite advances in medical treatment for ovarian cancer, little has been done to improve the behavioral-emotional outcomes of couples facing recently diagnosed advanced ovarian cancer. This shortcoming is remarkable because ovarian cancer is the 2nd most frequent gynecologic cancer in the U.S., the majority (75\%) of which presents as Stage III or IV disease at initial time of diagnosis, and in which almost $50 \%$ of the women are 63 years of age or older, often with multi-morbidity (2 or more conditions) [1] [18] [19]. Medical treatment is extremely 
difficult and involves extensive surgery (diagnostic and debulking and symptom-inducing chemotherapy) [20]. Sadly, despite multiple cycles of chemotherapy [21], $60 \%-85 \%$ of patients' with advanced ovarian cancer will recur and only $25 \%$ will survive 5 years after diagnosis [20] [22].

It is extremely difficult to describe the devastation women and their spouse caregivers experience when they are told at initial diagnosis that she has advanced ovarian cancer [23]. One day the woman is asymptomatic or experiences minimal abdominal discomfort; the next day she is told she needs diagnostic surgery; post-surgery she is told she has advanced disease. Yes, there are other types of advanced cancers that cause distress, but the illness trajectory of advanced ovarian cancer is arguably among the most rapidly downhill and among the worst prognoses of female cancers.

Depressed mood in ovarian cancer patients is significantly elevated compared to population norms; $29 \%$ - $47 \%$ reach or exceed clinical levels of anxiety or depression or both [8] [9] [10]. Women are emotionally devastated by the disease [24] [25] [26]; harbor substantial fears about dying from the cancer [27]; and fear recurrence even at initial time of diagnosis [28].

Spouse caregivers are also devastated by the disease and the magnitude of this distress goes well beyond simple "caregiving burden" [4] [6]. Almost half of the spouses (39.4\%) have clinically eolevated scores on anxiety or depressed mood or both [7], both of which are associated with higher distress in cancer patients [5], [7] [8] [9] [10] [11]. Depressed mood can also deleteriously affect the support the spouse is able to offer the patient, strain the marriage and relationship, and negatively impact the ways couples deal with their cancer-related problems and challenges [11] [12] [29].

Spouse caregivers report feeling unprepared for all aspects of caregiving; struggle with what to say or do to support the patient; commonly misjudge how to help her, emphasizing instrumental, not interpersonal support; and feel helpless and a lack of control that, despite best medical treatment, they could lose her to the disease [25] [29] [30]. Social support, when present, significantly predicts the patient's higher quality of life [8]; it is essential to her healing. But its absence or diminished levels of support set up a cycle of distancing that works against her well-being [12] [31].

In addition to the shock and exacting nature of the woman's advanced ovarian cancer, elderly spouse caregivers have multiple morbidities that add to their distress [18] [19] [32]. In a recently completed population based study, the prevalence of multi-morbidity ( $\geq 2$ conditions) increased steeply with older age and reached $77.3 \%$ at 65 years and older [19].

Despite the potential vulnerability of spouse caregivers and the magnitude of their distress, they and the diagnosed partner have been seriously underserved in prior intervention studies. The illusion is that there are hundreds of intervention studies involving spouse caregivers or couples that have addressed couples' and caregivers' distress, interpersonal support, or communication. The reality is that most of these studies have not focused on dyadic adjustment [33] [34] [35]. Even 
when intervention studies have included information on the importance of interpersonal support or the quality of marital communication about the cancer, none have focused on advanced stage ovarian cancer; none have trained or coached the caregiver to actually attain the skills or confidence to emotionally support the diagnosed woman with the illness; none have helped the spouse caregivers enact the self-care or supportive communication skills in real time with a nurse coach; none have positioned the spouse caregiver as an active agent to help the diagnosed wife emotionally heal and manage the toll of the cancer; and none have included at-home exercises for the spouse caregiver to carry out with the diagnosed partner in real time.

The most recently completed trials by McLean's [16] and Northouse's [17] teams are highly relevant to this study. Both interventions involved couples dealing with advanced cancer (of mixed types) and both stressed the importance of marital communication and interpersonal support. However, both of these interventions confused discussing communication and support with the caregiver with building those skills. Furthermore, both relied on conjoint delivery, adding to the patients' and caregivers' time burden. With ovarian cancer, such travel or demands are unrealistic, given the patient's surgery and symptom load. Furthermore, Northouse's [17] intervention did not significantly improve marital communication or dyadic support and McLean's [16] intervention did not significantly reduce patients' or spouse caregivers' depressed mood.

What is needed is a paradigm shift in spouse caregiver research in which spouse caregivers are seen as part of the healing team [36]. This is more than being a "coach" for medication management; it is about being an active agent with the potential to positively enhance the Quality of Life (QOL) outcomes for the patient, the caregiver, and their relationship. The Taking Care of Her (TCH) Program is delivered to the spouse caregiver by telephone and includes training and structured exercises with a nurse; exercises designed to help caregivers gain the requisite skills to carry out interpersonal support that the patient experiences as supportive; assists spouses to transfer their acquired competencies to actual interactions and support to the patient in their home; and helps caregivers build and integrate a specific and sustainable self-care plan for themselves so that they can be attentive and responsive to the patient in the long-term, not just during the acute initial phase of treatment. To further reduce burden on the spouse caregiver and to increase accessibility and sustainability, the intervention needed to be delivered through a user-friendly channel that does not require travel or time away from home, the telephone.

The structure and form of the TCH Program were designed to be easily delivered by telephone by Masters prepared patient educators (nurses, social workers, certified health educators, psychologists, or mental health counselors) and not require clinic space or a doctorally prepared therapist. A telephone-delivered program also has the potential to reach spouse caregivers distant from the clinic and for whom travel, access, funds, and availability pose a burden. Longer range, the form of the TCH as a fully scripted intervention has the potential for training 
health-related personnel in diverse settings with diverse credentials.

The intervention tightly, not broadly, articulates with both the Relational Model of Adjustment to Cancer [5] [11] [12] [29] [37] [38] [39] and Bandura's Social Cognitive Theory [40] [41] [42]. Social Cognitive Theory provides the structure and organization for each intervention session, including the mechanisms in the theory that are known to change spouse caregivers' skills and self-efficacy.

The specially designed exercises were developed to add to the caregiver's skills to interact with the patient under exceptionally challenging situations caused by the ovarian cancer, including when the patient says things like: "I don't think I will survive this." Or, "We need to plan for my not being alive by this time next year." Each skill exercise is broken into its component parts and is systematically worked by the patient educator with the caregiver in each session. There is no focus in Taking Care of Her on teaching about the biology, treatment of, or symptom management of the cancer. Instead, the total focus is on creating communication and support competencies in the caregiver that have the potential to relieve the patient's distress and feel supported as well as add to the caregiver's own self-care.

The intervention was delivered through the simple telephone (land line or cell phone) to accommodate the realities of both younger and older patients and caregivers. Seniors continue to lag behind younger Americans when it comes to technical adoption and many seniors remain largely unattached from online and mobile life $-41 \%$ do not use the internet at all, 53\% do not have broadband access at home, and 23\% do not use cell phones. Furthermore, internet use and broadband adoption each drop off dramatically around age 75 [43]. Recent completed research also shows that the simple telephone can attain or exceed the benefits of using more complex telehealth methods to enhance the quality of life of patients with a different type of female cancer and their caregivers [44]. Rather than add web-based or other telehealth technologies, which we initially considered, the intervention uses a method of reaching and intervening with both younger and elderly caregivers for whom travel is costly or time prohibitive, including those who would likely have multi-morbidities. Longer-range, the reach and saturation of the telephone has exceptionally high potential for national dissemination and integration into provider settings.

\subsection{Study Design/Protocol/Study Measures}

The proposed study was a single-group, pre-posttest design (within group analysis). Spouse caregivers and diagnosed wives served as their own controls. Participants were eligible if the wife was diagnosed at initial time of diagnosis with Stages III or IV ovarian cancer; was within 8 months of initial diagnosis; read and wrote English as 1 of their languages of choice; was legally married or co-inhabiting in an intimate relationship in the same domicile for 6 or more months; had access to a telephone; and had no prior cancer within the recent 5 years, except basal or squamous cell carcinoma. Patients were not eligible if they were unable to read or write in English, had early stage ovarian cancer, were in- 
itially diagnosed with early stage disease that then became advanced stage disease; were single women with no intimate partner; had no access to a telephone; or were diagnosed with additional types of cancer.

After approval of the Human Subjects Committee, participants were recruited from medical practices of physicians in the Pacific NW through a site intermediary. When diagnosed patients verbally agreed to participate, their spouse caregivers were contacted. Pending verbal approval to enroll, they were mailed a study packet containing separate consent forms, baseline and post-intervention questionnaires, and program materials [each intervention session was sealed in a separate envelope]. The patient educator contacted the diagnosed wife and spouse caregiver after receipt of the packet to assist in interpreting the consent form and to answer questions about study questionnaires. Once signed consent forms and baseline questionnaires were received, the patient educator scheduled the first telephone intervention session with the spouse caregiver. Five intervention sessions (lasting 30 - 60 minutes each) were scheduled at 2-week intervals. At immediate completion of the $5^{\text {th }}$ session, the caregiver was asked to complete and return the post-intervention questionnaires in a provided stamped, addressed envelope.

\subsection{Study Measures}

Diagnosis, demographic and treatment-related variables were obtained through medical record and self-report. Data on standardized measures of adjustment were obtained separately from spouse caregivers and diagnosed wives.

\subsection{Self-Efficacy Scale}

Spouses' self-efficacy was measured by the Cancer Self-Efficacy Scale (CASE), a 19-item self-report measure of the degree of self-confidence spouses had in supporting their wife and carrying out their own self-care [17] [30] [39]. The questionnaire consists of two subscales: a Wife-focused subscale and a Self-care focused subscale. Structured response options range from "Not at all confident" (1) to "Very confident" (10).

The Wife-focused subscale (14 items) measures spouse caregivers' confidence in being able to talk with the patient about her cancer-related concerns and ways to be supportive to her, e.g., "I know what to do to be supportive to my wife/ partner about the ovarian cancer" and "I know how to help my wife/partner express her worries and concerns about the ovarian cancer." The Self-care focused subscale ( 5 items) measures spouse caregivers' confidence in helping them deal with their own demands and challenges from the ovarian cancer, e.g., "I know what resources to use to help me personally cope with my wife's ovarian cancer." The internal consistency reliability for the Total scale was 0.95 and 0.95 for the Wife-focused and 0.81 for the Self-care focused subscales.

\subsection{Depressed Mood}

Depressed mood was measured by the Center for Epidemiologic Studies-De- 
pression Scale (CES-D), a 20-item scale that measures the recent occurrence of symptoms of depression [45] [46]. For each reported symptom, the respondent indicates the frequency of that symptom in the past week, from "rarely or none of the time (less than 1 day)" to "most or all of the time (5 - 7 days)." Internal consistency reliability has been reported in three samples from the general population and ranged between 0.84 and 0.85 [46] and was 0.85 or higher in more recent studies with cancer patients [14] [45]. The validity of the measure is well-established, including its association with the broader concept of "distress" in cancer-related research. A score of 16 or greater is suggestive of clinical depression [46].

\subsection{Anxiety}

Spouse caregivers' and patients' anxiety were measured by the state component of the Spielberger State-Trait Anxiety Inventory (STAI), a 20-item self-report questionnaire which evaluates feelings of apprehension, tension, nervousness, and worry "right now, at this moment" [47] [48] [49]. Response options read," I am tense;" "I feel indecisive;" and "I feel pleasant." Internal consistency reliability was 0.90 or above in community and population samples [50].

\subsection{Marital Communication}

Marital communication was measured by the Mutuality \& Interpersonal Sensitivity Scale (MIS), a self-report questionnaire that measures both the content and ways in which couples communicate with each other about the ovarian cancer [17] [30] [39] [51]. The measure consists of two subscales: Open Communication and Expressing Sad Feelings. Higher scores denote higher quality marital communication.

Example items on the Open Communication subscale read: "We confide in each other about the ovarian cancer;" and "We spend a lot of time talking about how things are going with the ovarian cancer." Example items on Expressing Sad Feelings subscale read: "We don't talk together about the sadness I feel about the ovarian cancer" and "We limit our talk together about difficult issues caused by the ovarian cancer." The internal consistency reliabilities for the wives' and spouses' Open Communication subscale are 0.92 and 0.86, respectively. The internal consistency reliabilities for wives' and spouses' Expressing Sad Feelings subscale are 0.88 and 0.82 , respectively.

\subsection{Spouse’s Skills}

Spouses' skills were measured by the What I Do for Her Checklist, a 26-item spouse-reported measure that consists of two subscales: a wife support subscale and a self-care subscale. The spouse is asked whether or not each item (skill) describes him/herself on a scale of 1 ("never") to 5 ("all of the time") during the recent two weeks. The wife support subscale (6 items) measures spouses' ways of eliciting and interpersonally responding to her. Example items include: "I try to get my wife/partner to talk about her ovarian cancer when it is bothering her" 
and "I ask my wife/partner about specific ways I can be supportive to her about her ovarian cancer." The self-care subscale measures spouses' ways of managing their own cancer-related stress. Example items include: "I take regular time out for myself;" and "I use support from others to help me cope with her ovarian cancer." The internal consistency reliability for the wife support subscale was 0.64 and 0.51 for the self-care subscale.

\subsection{Wife's Appraisal of Spouse's Support}

The wife's appraisal of her spouse's interpersonal support was measured by the What He Does for Me Questionnaire, an 18-item cancer-specific measure of support completed by the diagnosed woman. The scale measures her perception of specific, observable behaviors of support she receives from her spouse related to her ovarian cancer. Each item asks her whether the statement describes her spouse's behaviors within the recent two weeks on a scale of 1 ("Never") to 5 ("All of the time"). Example items read, "My husband/partner listens to me when I tell him/her sad or negative things about my ovarian cancer;" "My husband/partner starts up conversations with me when I'm sad or worried about my ovarian cancer;" "My husband/partner accepts my feelings about my ovarian cancer, no matter what my feelings;" and "My husband/partner talks with me in ways that draw out my fears or concerns about my ovarian cancer." The internal consistency reliability is 0.88 .

\section{Study Sample}

A total of 12 study participants were enrolled and completed the 5-session program, 6 spouse caregivers and 6 diagnosed wives. See Table 1. Women who were diagnosed with ovarian cancer averaged 63.3 years of age (SD 9.1 years); range 49 - 74, median 66. Women averaged 18.0 (SD 1.7) years of education; median 17.5 years.

Five of the women were Caucasian and 1 was Hispanic. Spouse caregivers of the women included 5 men and 1 woman all of whom were Caucasian. Caregivers averaged 65.7 (SD 9.4) years of age and had an average of 17.0 (SD 2.2) years of education. Couples were in their relationship an average of 33.7 (SD 18.6) years.

Women had been diagnosed an average of 3.6 (SD 1.5) months at time of entry into the study. All women were diagnosed with Stage III disease: two were Stage IIIB and four were Stage IIIC. Women at baseline had a mean depressed mood score (CES-D) of 20.0 (SD 4.4), and all 6 of the women had CES-D scores at or above the clinical cutoff score of 16 . The average anxiety (STAI) scores for these same women was 34.5 (SD 11.6). Three women had STAI scores above the clinical cutoff of 40 .

At baseline, spouse caregivers of the women had an average CES-D score of 12.8 (SD 5.0). One participant scored 22 on the CES-D, above the clinical cutoff. Spouse caregivers' average state anxiety score on the STAI was 33.2 (SD 8.1). Two partners had an STAI score above the clinical cutoff with values of 40 and 
42.

The majority of women had surgically undergone hysterectomy, bilateral salingo-oophorectomy, radical debulking and bowel resection. At the time of this trial, all had received or were actively receiving Carboplatin, Cisplatin, and Taxol.

\section{Study Results}

\subsection{Study Aim 1-Feasibility}

Forty-three percent (43\%) of eligible cases were successfully recruited into the study. Eligible patients who declined participation reported they were not interested in participating, felt they were too far out from time of diagnosis, or their spouse caregiver was not well. In two cases, eligible patients died between being referred for recruitment and being contacted by the study team. (This rate of refusals of eligible patients requires that sufficient resources be allocated for recruitment in future studies with this population.)

Intervention dosage and fidelity was at the highest level for all sessions for both patient educators for all 5 intervention sessions for all patient educators. Each session had 19 - 36 criteria against which the patient educator's behavior was reviewed. Scores for each criterion ranged from $1-3$. All but 1 session by 1 patient educator scored 3 out of 3 . These data told us that the patient educator was able to deliver the content of each intervention session by telephone as designed in the patient educator manual.

Study measures were sensitive to changes between baseline and post-intervention scores. There was also no evidence of floor or ceiling effects.

\subsection{Study Aim 2-Short-Term Impact}

Tables 1-6 contain a summary of study outcomes, comparing baseline with post-intervention scores on the standardized measures of spouses' and patients' depressed mood (CES-D), anxiety (STAI), quality of marital communication for both total and subscales (MIS), and spousal support (What He Does for Me); spouse caregivers' skills (What I Do for Her); and spouse caregiver self-efficacy for both total and subscales (Cancer Self-efficacy Scale). The Wilcoxon Signed Rank tests, a non-parametric equivalent of the $t$-test for dependent samples, was used to test for statistical significance.

Results revealed improvements on the standardized outcome measures for both diagnosed wives and spouse caregivers. These improvements were statistically significant on measures of spouse caregivers' skills (What I Do for Her) and self-efficacy (CASE), including both subscales (Wife-focused and Self-care-focused efficacy). There were also statistical tendencies $(\mathrm{p}=0.06$ to $\mathrm{p}=0.10)$ for wives to more positively appraise spouses' support (What He Does for Me) and for both members of the couple to score higher on the quality of their marital communication about the cancer, namely, their open communication with each other (MIS Open Communication subscale). Additionally, wives scored higher 
Table 1. Summary of study sample for diagnosed wives and spouse caregivers.

\begin{tabular}{|c|c|c|c|c|c|c|}
\hline \multicolumn{7}{|c|}{ Diagnosed Wives' Demographics } \\
\hline $\begin{array}{c}\text { CODE } \\
\text { NUMBER }\end{array}$ & Age & Education & Ethnicity & $\begin{array}{l}\text { Treatment } \\
\text { in last } 6 \\
\text { months }\end{array}$ & $\begin{array}{l}\text { Months } \\
\text { since } \\
\text { diagnosis }\end{array}$ & Stage \\
\hline 8001 & 74 & $\begin{array}{l}\text { College } \\
\text { graduate }\end{array}$ & Caucasian & Yes & 3.45 & IIIC \\
\hline 8003 & 49 & $\begin{array}{l}\text { Master's } \\
\text { degree }\end{array}$ & Hispanic & Yes & 2.37 & IIIB \\
\hline 8004 & 57 & $\begin{array}{l}\text { College } \\
\text { graduate }\end{array}$ & Caucasian & Yes & 1.31 & IIIC \\
\hline 8005 & 66 & $\begin{array}{l}\text { College } \\
\text { graduate }\end{array}$ & Caucasian & Yes & 1.94 & IIIC \\
\hline 8006 & 70 & $\begin{array}{l}\text { College } \\
\text { graduate }\end{array}$ & Caucasian & Yes & 5.58 & IIIC \\
\hline 8010 & 64 & $\begin{array}{l}\text { College } \\
\text { graduate }\end{array}$ & Caucasian & Yes & 7.19 & IIIC \\
\hline \multicolumn{7}{|c|}{ Spouse Caregivers' Demographics } \\
\hline $\begin{array}{c}\text { CODE } \\
\text { NUMBER }\end{array}$ & Age & Gender & Education & Ethn & & $\begin{array}{l}\text { Years in } \\
\text { elationship }\end{array}$ \\
\hline 8001 & 79 & Male & College graduate & Cauc & & 53 \\
\hline 8003 & 53 & Female & Master's degree & Cauc & ian & 13 \\
\hline 8004 & 59 & Male & College graduate & Cauc & ian & 37.6 \\
\hline 8005 & 65 & Male & $\begin{array}{l}\text { Some college or } \\
\text { technical training }\end{array}$ & Cauc & ian & 27.1 \\
\hline 8006 & 73 & Male & College graduate & Cauc & ian & 56.4 \\
\hline 8010 & 65 & Male & Doctoral degree & Cauc & ian & 15 \\
\hline
\end{tabular}

Table 2. Study outcomes comparing baseline and post-intervention scoreson standardized measures of depressed mood and anxiety for diagnosed wives and spouse caregivers.

\begin{tabular}{|c|c|c|c|c|c|c|c|c|}
\hline \multirow[b]{2}{*}{$\begin{array}{c}\text { CODE } \\
\text { NUMBER }\end{array}$} & \multicolumn{2}{|c|}{$\begin{array}{c}\text { Patient Depressed } \\
\text { Mood }\end{array}$} & \multicolumn{2}{|c|}{$\begin{array}{c}\text { Spouse Depressed } \\
\text { Mood }\end{array}$} & \multicolumn{2}{|c|}{ Patient Anxiety } & \multicolumn{2}{|c|}{ Spouse Anxiety } \\
\hline & Pre-Test & Post-Test & Pre-Test & Post-Test & Pre-Test & Post-Test & Pre-Test & Post-Test \\
\hline $8001^{\mathrm{a}}$ & 16 & 12 & 10 & 3 & 20 & 23 & 31 & 23 \\
\hline 8003 & 16 & 13 & 22 & 31 & 30 & 22 & 42 & 43 \\
\hline 8004 & 25 & 15 & 11 & 4 & 45 & 40 & 38 & 24 \\
\hline $8005^{\mathrm{a}}$ & 18 & 24 & 11 & 6 & 46 & 60 & 40 & 23 \\
\hline $8006^{\mathrm{a}}$ & 26 & 12 & 8 & 6 & 43 & 23 & 26 & 31 \\
\hline 8010 & 19 & 9 & 15 & 4 & 23 & 25 & 22 & 30 \\
\hline Mean & 20.00 & 14.17 & 12.83 & 9.00 & 34.50 & 32.17 & 33.17 & 29.00 \\
\hline SD & 4.4 & 5.2 & 5.0 & 10.8 & 11.6 & 15.2 & 8.1 & 7.7 \\
\hline Median & 18.5 & 12.5 & 11 & 5 & 36.5 & 24 & 34.5 & 27 \\
\hline $\begin{array}{l}\text { Possible } \\
\text { range }\end{array}$ & \multicolumn{2}{|c|}{$0-60$} & \multicolumn{2}{|c|}{$0-60$} & \multicolumn{2}{|c|}{$20-80$} & \multicolumn{2}{|c|}{$20-80$} \\
\hline Cutoffs & \multicolumn{2}{|c|}{$\geq 16$} & \multicolumn{2}{|c|}{$\geq 16$} & \multicolumn{2}{|c|}{$>39$} & \multicolumn{2}{|c|}{$>39$} \\
\hline Wilcoxon ${ }^{\mathrm{b}}$ & \multicolumn{2}{|c|}{0.116} & \multicolumn{2}{|c|}{0.248} & \multicolumn{2}{|c|}{0.500} & \multicolumn{2}{|c|}{0.400} \\
\hline
\end{tabular}

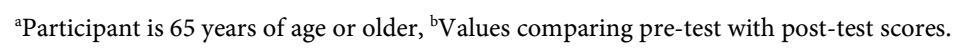


Table 3. Study outcomes comparing baseline and post-intervention scores on standardized measures of diagnosed wives'appraisal of spouse support and spouse caregivers' report of spouse support.

\begin{tabular}{|c|c|c|c|c|}
\hline \multirow[t]{2}{*}{ CODE NUMBER } & \multicolumn{2}{|c|}{ What He Does for Me } & \multicolumn{2}{|c|}{ What I Do for Her Spouse Skills } \\
\hline & Pre-Test & Post-Test & Pre-Test & Post-Test \\
\hline $8001^{\mathrm{a}}$ & 81 & 81 & 91 & 106 \\
\hline 8003 & 56 & 74 & 84 & 97 \\
\hline 8004 & 61 & 70 & 77 & 89 \\
\hline $8005^{\mathrm{a}}$ & 40 & 59 & 94 & 93 \\
\hline $8006^{\mathrm{a}}$ & 60 & 69 & 82 & 96 \\
\hline 8010 & 73 & 85 & 89 & 98 \\
\hline Mean & 61.83 & 73.00 & 86.17 & 96.50 \\
\hline $\mathrm{SD}$ & 14.2 & 9.3 & 6.3 & 5.7 \\
\hline Median & 60.5 & 72 & 86.5 & 96.5 \\
\hline Possible range & \multicolumn{2}{|c|}{$18-90$} & \multicolumn{2}{|c|}{$26-130$} \\
\hline Wilcoxon $^{\mathrm{b}}$ & \multicolumn{2}{|c|}{0.066} & \multicolumn{2}{|c|}{0.028} \\
\hline
\end{tabular}

${ }^{\mathrm{a}}$ Participant is 65 years of age or older, ${ }^{\mathrm{b}}$ Values comparing pre-test with post-test scores.

Table 4. Study outcomes comparing baseline and post-intervention scores for diagnosed wives on the quality of marital communication about the cancer.

\begin{tabular}{|c|c|c|c|c|c|c|}
\hline \multirow[b]{2}{*}{$\begin{array}{c}\text { CODE } \\
\text { NUMBER }\end{array}$} & \multicolumn{2}{|c|}{ Wife MIS Total } & \multicolumn{2}{|c|}{$\begin{array}{c}\text { Wife MIS Expressing } \\
\text { Sad Thoughts }\end{array}$} & \multicolumn{2}{|c|}{$\begin{array}{l}\text { Wife MIS Open } \\
\text { Communication }\end{array}$} \\
\hline & Pre-Test & Post-Test & Pre-Test & Post-Test & Pre-Test & Post-Test \\
\hline $8001^{\mathrm{a}}$ & 115 & 112 & 45 & 45 & 45 & 45 \\
\hline 8003 & 95 & 107 & 32 & 40 & 41 & 45 \\
\hline 8004 & 72 & 81 & 27 & 30 & 30 & 34 \\
\hline $8005^{\mathrm{a}}$ & 58 & 82 & 21 & 33 & 26 & 32 \\
\hline $8006^{a}$ & 74 & 91 & 24 & 28 & 32 & 42 \\
\hline 8010 & 114 & 111 & 45 & 43 & 44 & 43 \\
\hline Mean & 88.00 & 97.33 & 32.33 & 36.50 & 36.33 & 40.17 \\
\hline $\mathrm{SD}$ & 23.7 & 14.4 & 10.5 & 7.1 & 8.0 & 5.7 \\
\hline Median & 84.5 & 99 & 29.5 & 36.5 & 36.5 & 42.5 \\
\hline $\begin{array}{l}\text { Possible } \\
\text { range }\end{array}$ & \multicolumn{2}{|c|}{$23-115$} & \multicolumn{2}{|c|}{$9-45$} & \multicolumn{2}{|c|}{$9-45$} \\
\hline Wilcoxon $^{\mathrm{b}}$ & \multicolumn{2}{|c|}{0.115} & \multicolumn{2}{|c|}{0.080} & \multicolumn{2}{|c|}{0.078} \\
\hline
\end{tabular}

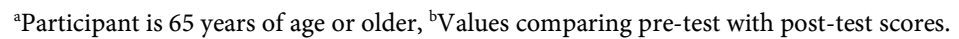

on communicating their sad thoughts and feelings to their spouse caused by the ovarian cancer (MIS Expressing Sad Thoughts subscale). Even when improvements failed to reach statistical significance, likely due to the small sample size, wives and caregivershad reduced scores on depressed mood and anxiety at posttest compared to baseline scores. 
Table 5. Study outcomes comparing baseline and post-intervention scores for spouse caregivers on the quality of marital communication about the cancer.

\begin{tabular}{|c|c|c|c|c|c|c|}
\hline \multirow[b]{2}{*}{$\begin{array}{c}\text { CODE } \\
\text { NUMBER }\end{array}$} & \multicolumn{2}{|c|}{ Spouse MIS Total } & \multicolumn{2}{|c|}{$\begin{array}{c}\text { Spouse MIS Expressing } \\
\text { Sad Thoughts }\end{array}$} & \multicolumn{2}{|c|}{$\begin{array}{l}\text { Spouse MIS Open } \\
\text { Communication }\end{array}$} \\
\hline & Pre-Test & Post-Test & Pre-Test & Post-Test & Pre-Test & Post-Test \\
\hline $8001^{a}$ & 99 & 107 & 34 & 40 & 39 & 39 \\
\hline 8003 & 88 & 105 & 23 & 37 & 36 & 38 \\
\hline 8004 & 81 & 89 & 30 & 28 & 31 & 36 \\
\hline $8005^{\mathrm{a}}$ & 91 & 100 & 30 & 36 & 35 & 36 \\
\hline $8006^{\mathrm{a}}$ & 88 & 94 & 30 & 35 & 32 & 32 \\
\hline 8010 & 101 & 94 & 37 & 29 & 36 & 38 \\
\hline Mean & 91.33 & 98.17 & 30.67 & 34.17 & 34.83 & 36.50 \\
\hline SD & 7.5 & 7.0 & 4.7 & 4.7 & 2.9 & 2.5 \\
\hline Median & 89.5 & 97 & 30 & 35.5 & 35.5 & 37 \\
\hline Possible range & \multicolumn{2}{|c|}{$23-115$} & \multicolumn{2}{|c|}{$9-45$} & \multicolumn{2}{|c|}{$8-40$} \\
\hline Wilcoxon ${ }^{\mathrm{b}}$ & \multicolumn{2}{|c|}{0.074} & \multicolumn{2}{|c|}{0.344} & \multicolumn{2}{|c|}{0.066} \\
\hline
\end{tabular}

${ }^{\mathrm{a}}$ Participant is 65 years of age or older, ${ }^{\mathrm{b}}$ Values comparing pre-test with post-test scores.

Table 6. Study outcomes comparing baseline and post-intervention scores for spouse caregivers' self-efficacy.

\begin{tabular}{|c|c|c|c|c|c|c|}
\hline \multirow[b]{2}{*}{ CODE NUMBER } & \multicolumn{2}{|c|}{ Spouse CASE Total } & \multicolumn{2}{|c|}{ CASE Self-Focused } & \multicolumn{2}{|c|}{ CASE Wife-focused } \\
\hline & Pre-Test & Post-Test & Pre-Test & Post-Test & Pre-Test & Post-Test \\
\hline $8001^{\mathrm{a}}$ & 166 & 183 & 39 & 47 & 127 & 136 \\
\hline 8003 & 93 & 164 & 22 & 43 & 71 & 121 \\
\hline 8004 & 140 & 158 & 36 & 41 & 104 & 117 \\
\hline $8005^{\mathrm{a}}$ & 132 & 156 & 31 & 40 & 101 & 116 \\
\hline $8006^{\mathrm{a}}$ & 134 & 167 & 34 & 44 & 100 & 123 \\
\hline 8010 & 135 & 158 & 39 & 43 & 96 & 115 \\
\hline Mean & 133.33 & 164.33 & 33.50 & 43.00 & 99.83 & 121.33 \\
\hline SD & 23.4 & 10.1 & 6.4 & 2.4 & 17.9 & 7.8 \\
\hline Median & 134.5 & 161 & 35 & 43 & 100.5 & 119 \\
\hline Possible range & \multicolumn{2}{|c|}{$0-190$} & \multicolumn{2}{|c|}{$0-50$} & \multicolumn{2}{|c|}{$0-140$} \\
\hline Wilcoxon $^{\mathrm{b}}$ & \multicolumn{2}{|c|}{0.028} & \multicolumn{2}{|c|}{0.028} & \multicolumn{2}{|c|}{0.028} \\
\hline
\end{tabular}

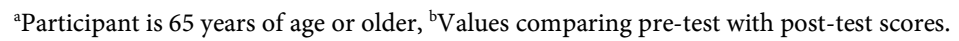

\subsection{Gains Attributed by Patients and Spouse Caregivers to TCH Program}

In addition to examining outcomes on standardized questionnaires, study participants were interviewed after exiting the TCH Program by a specially trained phone worker who was masked on the content of the intervention. Participants were asked "What if anything did you gain from the program? What in particular stands out for you about the program? If you were to tell another woman whose spouse or partner is eligible for the program, what would you say to her? 
What were negative aspects, if any, for you about the program? If you would want to improve the program, in what ways could it be improved? What if anything would you like to tell us about the program that we have not asked?"Each interview was digitally audio-recorded, transcribed verbatim, verified for transcription accuracy, and content analyzed; themes are summarized below from caregivers and wives.

Spouse caregivers offered detailed examples of improvements in communicating with their wives about the cancer; in gaining ways to rethink how they did not need to control everything; learning ways to take care of themselves and to calm down and re-energize; gaining a new and better perspective on their relationship with their wife; and in acquiring specific communication strategies that helped them help their wife disclose her thoughts and feelings. Diagnosed wives reported gaining a heightened sense of personal security; felt their spouse deeply listened to and did not judge what the wife said; and claimed that the program helped them feel they were "fighting the cancer together."

\section{Discussion of Results}

The TCH Program resulted in diminished distress (anxiety and depressed mood); significantly improved the quality of marital communication about the cancer; increased the diagnosed wife's positive appraisal of her spouse's support; and significantly increased the spouse caregiver's skills and confidence in helping the diagnosed wife and themselves better manage the emotional toll of the illness. Overall, results suggest that a brief, fully scripted skill-building educational counseling program delivered by telephone to spouse caregivers has the potential to enhance their own and their diagnosed wife's behavioral-emotional functioning during initial treatment for advanced stage ovarian cancer. Interview results confirmed the value of the program to both caregivers and patients, including the benefits wives reported from their spouses' participation.

The absence of statistically significant results on the standardized measures of depressed mood and anxiety was likely due to the small sample size. However, recall that changes, even if not statistically significant, were in the positive direction. Remarkably with this small sample of 12 participants, there were statistically significant improvements in spouse caregivers' skills (What I Do for Her) and self-confidence to manage (both subscales of the CASE). Results from the standardized questionnaires were also reflected in data obtained from the exit interviews.

\section{Study Limitations}

Study results should be viewed with caution. All measures were self-report measures and are at risk for recall, self-enhancing, or social desirability biases. The use of a single group (within-subjects) design prevents unconditionally attributing the short-term impact of the TCH Program on the observed outcomes. In addition, Type I error was likely inflated, given the small sample size and the number of pre-posttest comparisons that were computed. Study results are also 
limited to well-educated couples in long-term relationships and do not generalize to educationally challenged families, to couples in recent or short-term relationships, or to a non-English speaking population. All of these groups warrant further attention in future studies.

\section{Acknowledgements}

This study was made possible by research funds awarded from the de Tornyay Center for Healthy Aging and Training grants from the Jeanne Q. Benoliel Endowed Fellowship, the Emerging Technology Training Grant, the Taiwan Ministry of Education, the Saudi Arabian Cultural Mission, and the Hoffman \& Top Scholar Awards from the University of Washington, School of Nursing. The content of the manuscript is solely the responsibility of the authors. This manuscript is dedicated to Barbara and Dottie.

\section{References}

[1] American Cancer Society (2017) Cancer Facts and Figures, 2017. https://www.cancer.org/content/dam/cancer-org/research/cancer-facts-and-statistic s/annual-cancer-facts-and-figures/2017/cancer-facts-and-figures-2017.pdf

[2] Fitch, M.I., Gray, R.E. and Franssen, E. (2001) Perspectives on Living with Ovarian Cancer: Older Women's Views. Oncology Nursing Forum, 28, 1433-1442.

[3] Myers Virtue, S., Manne, S.L., Ozga, M., Kissane, D.W., Rubin, S., Heckman, C., et al. (2014) Cancer-Related Concerns among Women with a New Diagnosis of Gynecological Cancer: An Exploration of Age Group Differences. International Journal of Gynecological Cancer, 24, 165-171. https://doi.org/10.1097/IGC.0000000000000010

[4] Beesley, V.L., Price, M.A. and Webb, P.M. (2011) Loss of Lifestyle: Health Behaviour and Weight Changes after Becoming a Caregiver of a Family Member Diagnosed with Ovarian Cancer. Supportive Care in Cancer, 19, 1949-1956. https://doi.org/10.1007/s00520-010-1035-2

[5] Fang, C.Y., Manne, S.L. and Pape, S.J. (2001) Functional Impairment, Marital Quality, and Patient Psychological Distress as Predictors of Psychological Distress among Cancer Patients' Spouses. Health Psychology, 20, 452-457. https://doi.org/10.1037/0278-6133.20.6.452

[6] Price, M.A., Butow, P.N., Costa, D.S., King, M.T., Aldridge, L.J., Fardell, J.E., et al. (2010) Prevalence and Predictors of Anxiety and Depression in Women with Invasive Ovarian Cancer and Their Caregivers. Medical Journal of Australia, 193, S52S57.

[7] Braun, M., Mikulincer, M., Rydall, A., Walsh, A. and Rodin, G. (2007) Hidden Morbidity in Cancer: Spouse Caregivers. Journal of Clinical Oncology, 25, 48294834. https://doi.org/10.1200/JCO.2006.10.0909

[8] Hipkins, J., Whitworth, M., Tarrier, N. and Jayson, G. (2004) Social Support, Anxiety and Depression after Chemotherapy for Ovarian Cancer: A Prospective Study. British Journal of Health Psychology, 9, 569-581. https://doi.org/10.1348/1359107042304542

[9] Lowe, T., Ferrell, B. and Leong, L. (2007) Quality-of-Life Issues in the Management of Epithelial Ovarian Cancer. Current Treatment Options in Oncology, 8, 402-416. https://doi.org/10.1007/s11864-007-0049-6 
[10] Passik, S.D. and Kirsh, K.L. (2005) A Pilot Examination of the Impact of Cancer Patients' Fatigue on Their Spousal Caregivers. Palliative and Supportive Care, 3, 273 279. https://doi.org/10.1017/S1478951505050431

[11] Manne, S. and Glassman, M. (2000) Perceived Control, Coping Efficacy, and Avoidance Coping as Mediators between Spouses' Unsupportive Behaviors and Cancer Patients' Psychological Distress. Health Psychology, 19, 155-164. https://doi.org/10.1037/0278-6133.19.2.155

[12] Manne, S.L. (1999) Intrusive Thoughts and Psychological Distress among Cancer Patients: The Role of Spouse Avoidance and Criticism. Journal of Consulting and Clinical Psychology, 67, 539-546. https://doi.org/10.1037/0022-006X.67.4.539

[13] Hendrix, C.C., Bailey Jr., D.E., Steinhauser, K.E., Olsen, M.K., Stechuchak, K.M., Lowman, S.G., et al. (2016) Effects of Enhanced Caregiver Training Program on Cancer Caregiver's Self-Efficacy, Preparedness, and Psychological Well-Being. Supportive Care in Cancer, 24, 327-336. https://doi.org/10.1007/s00520-015-2797-3

[14] Given, C., Given, B., Rahbar, M., Jeon, S., McCorkle, R., Cimprich, B., et al. (2004) Does a Symptom Management Intervention Affect Depression among Cancer Patients: Results from a Clinical Trial. Psycho-Oncology, 13, 818-830.

http://onlinelibrary.wiley.com/doi/10.1002/pon.807/abstract https://doi.org/10.1002/pon.807

[15] Hopkinson, J.B., Brown, J.C., Okamoto, I. and Addington-Hall, J.M. (2012) The Effectiveness of Patient-Family Carer (Couple) Intervention for the Management of Symptoms and Other Health-Related Problems in People Affected by Cancer: A Systematic Literature Search and Narrative Review. Journal of Pain and Symptom Management, 43, 111-142. https://doi.org/10.1016/j.jpainsymman.2011.03.013

[16] McLean, L.M., Walton, T., Rodin, G., Esplen, M.J. and Jones, J.M. (2013) A Couple-Based Intervention for Patients and Caregivers Facing End-Stage Cancer: Outcomes of a Randomized Controlled Trial. Psycho-Oncology, 22, 28-38. https://doi.org/10.1002/pon.2046

[17] Northouse, L.L., Mood, D.W., Schafenacker, A., Kalemkerian, G., Zalupski, M., LoRusso, P., et al. (2013) Randomized Clinical Trial of a Brief and Extensive Dyadic Intervention for Advanced Cancer Patients and Their Family Caregivers. PsychoOncology, 22, 555-563. https://doi.org/10.1002/pon.3036

[18] Stenholm, S., Westerlund, H., Head, J., Hyde, M., Kawachi, I., Pentti, J., et al. (2015) Comorbidity and Functional Trajectories from Midlife to Old Age: The Health and Retirement Study. Journals of Gerontology. Series A: Biological Sciences and Medical Sciences, 70, 332-338. https://doi.org/10.1093/gerona/glu113

[19] Rocca, W.A., Boyd, C.M., Grossardt, B.R., Bobo, W.V., Finney Rutten, L.J., Roger, V.L., et al. (2014) Prevalence of Multimorbidity in a Geographically Defined American Population: Patterns by Age, Sex, and Race/Ethnicity. Mayo Clinic Proceedings, 89, 1336-1349. https://doi.org/10.1016/j.mayocp.2014.07.010

[20] Ferrell, B., Cullinane, C.A., Ervine, K., Melancon, C., Uman, G.C. and Juarez, G. (2005) Perspectives on the Impact of Ovarian Cancer: Women's Views of Quality of Life. Oncology Nursing Forum, 32, 1143-1149. https://doi.org/10.1188/05.ONF.1143-1149

[21] Jensen, S.E., Rosenbloom, S.K., Beaumont, J.L., Abernethy, A., Jacobsen, P.B., Syrjala, K., et al. (2011) A New Index of Priority Symptoms in Advanced Ovarian Cancer. Gynecologic Oncology, 120, 214-219. https://doi.org/10.1016/j.ygyno.2010.09.025

[22] Wenzel, L.B., Huang, H.Q., Armstrong, D.K., Walker, J.L. and Cella, D. (2007) Health-Related Quality of Life During and after Intraperitoneal Versus Intravenous 
Chemotherapy for Optimally Debulked Ovarian Cancer: A Gynecologic Oncology Group Study. Journal of Clinical Oncology, 25, 437-443. https://doi.org/10.1200/JCO.2006.07.3494

[23] Seibaek, L., Petersen, L.K., Blaakaer, J. and Hounsgaard, L. (2012) Hoping for the Best, Preparing for the Worst: The Lived Experiences of Women Undergoing Ovarian Cancer Surgery. European Journal of Cancer Care (English Language Edition), 21, 360-371. https://doi.org/10.1111/j.1365-2354.2011.01313.x

[24] Ferrell, B., Smith, S.L., Cullinane, C.A. and Melancon, C. (2003) Psychological Well Being and Quality of Life in Ovarian Cancer Survivors. Cancer, 98, 1061-1071. https://doi.org/10.1002/cncr.11291

[25] Ponto, J.A. and Barton, D. (2008) Husbands' Perspective of Living with Wives' Ovarian Cancer. Psycho-Oncology, 17, 1225-1231. https://doi.org/10.1002/pon.1351

[26] Ozga, M., Aghajanian, C., Myers-Virtue, S., McDonnell, G., Jhanwar, S., Hichenberg, S., et al. (2015) A Systematic Review of Ovarian Cancer and Fear of Recurrence. Palliative and Supportive Care, 13, 1771-1780.

https://doi.org/10.1017/S1478951515000127

[27] Shinn, E.H., Taylor, C.L., Kilgore, K., Valentine, A., Bodurka, D.C., Kavanagh, J., et al. (2009) Associations with Worry about Dying and Hopelessness in Ambulatory Ovarian Cancer Patients. Palliative and Supportive Care, 7, 299-306. https://doi.org/10.1017/S1478951509990228

[28] Myers, S.B., Manne, S.L., Kissane, D.W., Ozga, M., Kashy, D.A., Rubin, S., et al. (2013) Social-Cognitive Processes Associated with Fear of Recurrence among Women Newly Diagnosed with Gynecological Cancers. Gynecologic Oncology, 128, 120-127. https://doi.org/10.1016/j.ygyno.2012.10.014

[29] Baider, L. and Kaplan De-Nour, A. (1988) Adjustment to Cancer: Who Is the Patient-The Husband or the Wife? Israel Journal of Medical Sciences, 24, 631-636. https://www.ncbi.nlm.nih.gov/pubmed/3204012

[30] Lewis, F.M., Fletcher, K.A., Cochrane, B.B. and Fann, J.R. (2008) Predictors of Depressed Mood in Spouses of Women with Breast Cancer. Journal of Clinical Oncology, 26, 1289-1295. https://doi.org/10.1200/jco.2007.12.7159

[31] Rodrigue, J.R. and Park, T.L. (1996) General and Illness-Specific Adjustment to Cancer: Relationship to Marital Status and Marital Quality. Journal of Psychosomatic Research, 40, 29-36. https://doi.org/10.1016/0022-3999(95)00540-4

[32] Hurria, A., Li, D., Hansen, K., Patil, S., Gupta, R., Nelson, C., et al. (2009) Distress in Older Patients with Cancer. Journal of Clinical Oncology, 27, 4346-4351. https://doi.org/10.1200/JCO.2008.19.9463

[33] Lewis, F.M. (2015) Invited Expert: State of Science Presentation on Informal Caregivers \& Dyadic Outcomes Proceedings National Cancer Institute, NIH, Bethesda, Maryland.

[34] Li, Q. and Loke, A.Y. (2014) A Systematic Review of Spousal Couple-Based Intervention Studies for Couples Coping with Cancer: Direction for the Development of Interventions. Psycho-Oncology, 23, 731-739. https://doi.org/10.1002/pon.3535

[35] Li, Q., Xu, Y., Zhou, H. and Loke, A.Y. (2015) The Development of a Complex Intervention in China: The "Caring for Couples Coping with Cancer '4cs' Programme" to Support Couples Coping with Cancer. BMC Palliative Care, 14, 64. https://doi.org/10.1186/s12904-015-0062-7

[36] Lewis, F.M. (2004) Family-Focused Oncology Nursing Research. Oncology Nursing Forum, 31, 288-292.

http://offcampus.lib.washington.edu/login?url=http://search.ebscohost.com/login.a 
spx?direct $=$ true $\& \mathrm{db}=\mathrm{ccm} \& \mathrm{AN}=106747503 \&$ site $=$ ehost-live https://doi.org/10.1188/04.ONF.288-292

[37] Lewis, F.M. (2010) The Family's "Stuck Points" in Adjusting to Cancer. In: Holland, J.C., Breitbart, W.S., Jacobsen, P.B., Lederbarg, M.S., Loscalzo, M.J. and MccorKle, R.S., Eds., Psycho-Oncology, Oxford University Press, Oxford, 511-515.

[38] Lewis, F.M., Hammond, M.A. and Woods, N.F. (1993) The Family's Functioning with Newly Diagnosed Breast Cancer in the Mother: The Development of an Explanatory Model. Journal of Behavioral Medicine, 16, 351-370. https://doi.org/10.1007/BF00844777

[39] Northouse, L.L., Mood, D.W., Schafenacker, A., Montie, J.E., Sandler, H.M., Forman, J.D., et al. (2007) Randomized Clinical Trial of a Family Intervention for Prostate Cancer Patients and Their Spouses. Cancer, 110, 2809-2818.

https://doi.org/10.1002/cncr.23114

[40] Bandura, A. (1986) Social Foundations of Thought and Action: A Social Cognitive Theory. Prentice Hall, Englewood Cliffs, NJ.

[41] Bandura, A. (2001) Social Cognitive Theory: An Agentic Perspective. Annual Review of Psychology, 52, 1-26. https://www.ncbi.nlm.nih.gov/pubmed/11148297 https://doi.org/10.1146/annurev.psych.52.1.1

[42] Bandura, A. (2004) Health Promotion by Social Cognitive Means. Health Education and Behavior, 31, 143-164. https://www.ncbi.nlm.nih.gov/pubmed/15090118 https://doi.org/10.1177/1090198104263660

[43] Smith, A. (2014) Older Adults and Technology Use. http://www.pewinternet.org/2014/04/03/older-adults-and-technology-use/

[44] Badger, T., Segrin, C., Pasvogel, A. and Lopez, A.M. (2013) The Effect of Psychosocial Interventions Delivered by Telephone and Videophone on Quality of Life in Early-Stage Breast Cancer Survivors and Their Supportive Partners. Journal of Telemedicine and Telecare, 19, 260-265.

http://offcampus.lib.washington.edu/login?url=http://search.ebscohost.com/login.a spx?direct=true $\& \mathrm{db}=\mathrm{ccm} \& A N=104108262 \&$ site $=$ ehost-live https://doi.org/10.1177/1357633X13492289

[45] Conerly, R.C., Baker, F., Dye, J., Douglas, C.Y. and Zabora, J. (2002) Measuring Depression in African American Cancer Survivors: The Reliability and Validity of the Center for Epidemiologic Study-Depression (CES-D) Scale. Journal of Health Psychology, 7, 107-114. http://hpq.sagepub.com/content/7/1/107 http://hpq.sagepub.com/content/7/1/107.full.pdf https://doi.org/10.1177/1359105302007001658

[46] Radloff, L.S. (1977) The CES-D Scale: A Self-Report Depression Scale for Research in the General Population. Applied Psychological Measurement, 1, 385-401.

http://apm.sagepub.com/content/1/3/385.abstract

http://apm.sagepub.com/content/1/3/385

https://doi.org/10.1177/014662167700100306

[47] Spielberger, C.D. (1983) Manual for the State-Trait Anxiety Inventory (Form Y). 2nd Edition, Consulting Psychologists Press, Palo Alto, CA.

[48] Spielberger, C.D., Sydeman, S.J., Owen, A.E. and Marsh, B.J. (1999) Measuring Anxiety and Anger with the State-Trait Anxiety Inventory (STAI) and the State-Trait Anger Expression Inventory (STAXI). In: Maruish, M.E., Ed., The Use of Psychological Testing for Treatment Planning and Outcomes Assessment. Instruments for Adults, Lawrence Erlbaum Associates, Mahwah, 993-1021.

[49] Spielberger, C.H. and Rickman, R.L. (1990) Assessment of State and Trait Anxiety. In: Sartorius, N., Andreoli, V.M., Cassano, G., Eisenberg, L. and Kielholz, P., Eds., 
Anxiety: Psychobiological and Clinical Perspectives, Hemisphere/Taylor \& Francis, WA, 69-84.

[50] Edwards, B. and Clarke, V. (2004) The Psychological Impact of a Cancer Diagnosis on Families: The Influence of Family Functioning and Patients' Illness Characteristics on Depression and Anxiety. Psycho-Oncology, 13, 562-576.

https://doi.org/10.1002/pon.773

[51] Fann, J.R., Thomas-Rich, A.M., Katon, W.J., Cowley, D., Pepping, M., McGregor, B.A., et al. (2008) Major Depression after Breast Cancer: A Review of Epidemiology and Treatment. General Hospital Psychiatry, 30, 112-126.

http://www.ghpjournal.com/article/S0163-8343(07)00220-4/abstract

https://doi.org/10.1016/j.genhosppsych.2007.10.008

Submit or recommend next manuscript to SCIRP and we will provide best service for you:

Accepting pre-submission inquiries through Email, Facebook, LinkedIn, Twitter, etc. A wide selection of journals (inclusive of 9 subjects, more than 200 journals)

Providing 24-hour high-quality service

User-friendly online submission system

Fair and swift peer-review system

Efficient typesetting and proofreading procedure

Display of the result of downloads and visits, as well as the number of cited articles

Maximum dissemination of your research work

Submit your manuscript at: http://papersubmission.scirp.org/

Or contact jct@scirp.org 